\title{
Short communication: Presynchronization for timed artificial insemination in grazing dairy cows by using progesterone for 14 days with or without prostaglandin $F_{2 \alpha}$ at the time of progesterone withdrawal
}

\author{
R. C. Escalante, S. E. Poock, D. J. Mathew, W. R. Martin, E. M. Newsom, S. A. Hamilton, K. G. Pohler, \\ and M. C. Lucy ${ }^{1}$ \\ Division of Animal Sciences and College of Veterinary Medicine, University of Missouri, Columbia 65211
}

\section{ABSTRACT}

Progesterone-containing devices can be inserted intravaginally for $14 \mathrm{~d}$ to presynchronize the estrous cycle for timed artificial insemination (TAI) in beef heifers ("14-day CIDR-PG" or "Show-Me-Synch" program). The progesterone treatment is effective for presynchronization because cattle develop a persistent dominant follicle during treatment that ovulates within $3 \mathrm{~d}$ after progesterone removal. The subsequent estrous cycle can be effectively used for a TAI program. Some cattle will retain a functional corpus luteum (CL) for the entire 14-d treatment period and will not be synchronized effectively because the interval to ovulation depends on the lifespan of their existing CL. The objective was to test the effect of a luteolytic dose of $\mathrm{PGF}_{2 \alpha}$ at progesterone removal for improving synchrony of estrus after treatment and increasing conception rate to a subsequent TAI in dairy cows. Postpartum cows ( $\mathrm{n}=$ 1,021) from 2 grazing dairy herds were assigned to 1 of 2 presynchronization programs that used a controlled internal drug releasing (CIDR) device containing progesterone: 14dCIDR (CIDR in, $14 \mathrm{~d}$, CIDR out; $\mathrm{n}$ $=523)$ or $14 \mathrm{dCIDR}+\mathrm{PGF}_{2 \alpha}$ (CIDR in, $14 \mathrm{~d}$, CIDR out, and $\left.\mathrm{PGF}_{2 \alpha} ; \mathrm{n}=498\right)$. Cows were body condition scored (BCS; 1 to 5 , thin to fat) and tail painted at CIDR removal. Paint score (PS) was recorded after CIDR removal $[\mathrm{PS}=0$ (all paint removed, indication of estrus), PS $=3$ (paint partially removed), or PS $=5$ (no paint removed; indication of no estrus)]. At $19 \mathrm{~d}$ after CIDR removal, all cows were treated with $\mathrm{PGF}_{2 \alpha}, 56 \mathrm{~h}$ later treated with $\mathrm{GnRH}$, and then $16 \mathrm{~h}$ later were TAI. Treating cows with $\mathrm{PGF}_{2 \alpha}$ at CIDR removal increased the percentage with $\mathrm{PS}=0$ within 5 d $\left(58.1 \%\right.$ vs. $68.9 \% ; 14 \mathrm{dCIDR}$ vs. $\left.14 \mathrm{dCIDR}+\mathrm{PGF}_{2 \alpha}\right)$. We found no effect of treatment, however, on conception rate at TAI (41.1\% vs. $43.6 \%$; respectively). The TAI conception rate increased with increasing BCS and

Received March 1, 2012

Accepted May 17, 2012

${ }^{1}$ Corresponding author: lucym@missouri.edu was greater for cows that had PS $=0$ within $5 \mathrm{~d}$ after CIDR removal. In summary, treating cows with PGF $_{2 \alpha}$ at CIDR removal increased the percentage of cows with all tail paint removed but did not increase percentage of pregnant cows after TAI.

Key words: controlled internal drug releasing (CIDR) device, timed artificial insemination, postpartum cow

\section{Short Communication}

One of the original methods to control the estrous cycle in dairy or beef cattle was by using progestogens [e.g., melengestrol acetate (MGA), medroxyprogesterone acetate, or progesterone; Christian and Casida, 1948; Patterson et al., 1989; Odde, 1990; Lauderdale, 2009]. Progestogens suppress estrus and inhibit ovulation. They also have the capacity to induce cyclicity in cows and heifers that are not cycling at the start of treatment (Anderson et al., 1996; Lucy et al., 2001). Feeding or treating cattle with progestogens for several weeks will synchronize estrus but the fertility of the estrus after long-term progestogen treatment is low (Patterson et al., 1989). The low fertility is caused by the development of a persistent dominant follicle during progestogen treatment (Ahmad et al., 1995; Revah and Butler, 1996; Roche et al., 1999). The persistent dominant follicle can ovulate but the oocyte within the follicle is infertile. Progestogens can be used, however, to presynchronize the estrous cycle before a timed AI (TAI) program that uses $\mathrm{PGF}_{2 \alpha}$ and $\mathrm{GnRH}$. For example, Schafer et al. (2007) demonstrated that MGA could be fed for $14 \mathrm{~d}$ before the initiation of a Co-Synch program on d 26. Leitman et al. (2009) found that an intravaginal controlled internal drug release (CIDR) device containing progesterone (Pfizer Animal Health, New York, NY) inserted for $14 \mathrm{~d}$ in beef heifers was an effective alternative to MGA feeding before a TAI.

If progesterone treatment begins in the mid or late phase of the estrous cycle, then a persistent dominant follicle develops when the corpus luteum $(\mathbf{C L})$ regresses during progestogen treatment (Sirois and Fortune, 1990; Kinder et al., 1996). If the progestogen treat- 
ment begins during the early phase of the estrous cycle (metestrus), then cattle have a shorter estrous cycle length (approximately $17 \mathrm{~d}$ in length; Garrett et al., 1988; Lynch et al., 1999). Depending on the day of the estrous cycle when progestogen treatment is started and the duration of progestogen treatment $(14 \mathrm{~d}$, for example; Leitman et al., 2009), a CL could be present and functional at the time of the progestogen removal. If a functional CL is still present at the time of progestogen removal, then time to estrus will increase and the synchronization of estrus after progestogen withdrawal will be less. We designed a field trial to test the effect of administering a luteolytic dose of $\mathrm{PGF}_{2 \alpha}$ at CIDR removal for improving synchrony of estrus after presynchronization. The response to the presynchronization treatment was assessed by measuring the tail paint score within 4 or $5 \mathrm{~d}$ after CIDR removal. Cows were then treated with $\mathrm{PGF}_{2 \alpha}$ and $\mathrm{GnRH}$ to determine if the treatment and the estrus response after CIDR withdrawal affected conception rate to TAI.

Postpartum dairy cows from 2 grazing dairy farms [North $(\mathrm{n}=544)$ and South $(\mathrm{n}=477)]$ located in southwest Missouri were used. The trial was conducted from April through July 2011. Both farms employed a seasonal grazing system. Cows were kept on pasture containing cereal ryegrass from February to April and on fescue and perennial ryegrass from April to July. All cows were milked twice a day on a rotary parlor and were supplemented with a TMR after each milking. Eligible cows were at least $30 \mathrm{~d}$ postpartum at the start of trial and were Holstein, Jersey, or crossbred. Approximately $29 \%$ of the cows enrolled in the trial were "carry-over" cows, meaning they had calved in the fall and were being inseminated in the spring.

Cows were assigned to 1 of 2 treatments (Figure 1 ). The first group $(\mathrm{n}=523)$ were treated with a CIDR device (1.38 g of progesterone; Pfizer Animal Health) for $14 \mathrm{~d}$ (14dCIDR). The second group $(\mathrm{n}=498)$ received a CIDR for $14 \mathrm{~d}$ and then on the day of CIDR removal received $5 \mathrm{~mL}$ of Lutalyse (i.m.; $25 \mathrm{mg}$ of dinoprost tromethamine, $\mathrm{PGF}_{2 \alpha}$; Pfizer Animal Health; 14dCIDR $\left.+\mathbf{P G F}_{2 \alpha}\right)$. Cows were body condition scored on a scale from 1 to 5 (thin to fat) at CIDR insertion and following CIDR removal. At the time of CIDR removal all cows were tail painted and then $4 \mathrm{~d}$ (North farm) or $5 \mathrm{~d}$ (South farm) later the paint score (PS) was recorded by using a scale of 0 (all paint removed; indication of estrus), 3 (paint partially removed), or 5 (no paint removed; indication of no estrus; Macmillan et al., 1988). At $19 \mathrm{~d}$ after CIDR removal, all cows were treated with $\mathrm{PGF}_{2 \alpha}, 56 \mathrm{~h}$ later treated with $\mathrm{GnRH}$ (2 $\mathrm{mL}$ Factrel; Pfizer Animal Health), and then $16 \mathrm{~h}$ later TAI. Eight bulls and 5 inseminators used for the TAI; bulls and inseminators were not confounded with farm.
The individual farms used an estrous detection program after the TAI. The program consisted of visual observation of estrus and examination of tail paint (cows were AI if they were observed in estrus or their tail paint was completely rubbed off; PS $=0$ ). Pregnancy diagnosis was performed by transrectal ultrasonography (EasiScan; BCF Technology, Rochester, MN) at $50 \mathrm{~d}$ after the TAI. Conception date was based on fetal size (crown rump length) and known AI dates. Cows pregnant to first AI (TAI) and second AI were determined. If a cow had not received a second insemination or was $<25$ $\mathrm{d}$ after second insemination when she was diagnosed pregnant, then she was not included in the analyses of second AI conception rate. The total number of pregnancies after first and second AI was based on known pregnancies at the time of pregnancy diagnosis (the cow had to be at least 25 d pregnant). Seventy-six cows (37 14dCIDR and 39 14dCIDR $+\mathrm{PGF}_{2 \alpha}$ ) had received a second AI but were $<25 \mathrm{~d}$ since the second insemination. These cows, if pregnant, did not contribute to the total number of pregnancies in the analyses.

The BCS score for the first observation (CIDR insertion) and the second observation (4 or $5 \mathrm{~d}$ after CIDR removal) were averaged and used in the statistical analyses. Pregnancy status was analyzed as the discrete dependent variable. Treatment, farm, AI technician, AI sire, breed, BCS, PS and calving season (carry-over or spring) were classified as independent variables. The GENMOD procedure of SAS (SAS Inst. Inc., Cary, $\mathrm{NC}$ ) was used for the statistical analysis. The frequency of cows with PS $=0,3$, or 5 within the respective treatments was tested using the chi-squared function within PROC FREQ of SAS. The frequency of cows having second AI on specific days after the TAI was also tested by using PROC FREQ. Statistical significance was declared as $P<0.05$.

We found no effect of treatment, farm, AI technician, AI sire, or breed on first AI conception rate (number of pregnant cows/number of AI; 432/1,021;42.3\%), on second AI conception rate $(100 / 369 ; 27.1 \%)$ or on the total number of pregnancies at the end of the first and second AI (number of pregnant cows/total cows; $532 / 1,021 ; 52.1 \%$; Table 1$)$. Interactions of main effects with farm were not significant. Treatment did affect $(P$ $<0.001)$ the frequency of cows with $\mathrm{PS}=0,3$, and 5 within $5 \mathrm{~d}$ after CIDR removal. The $14 \mathrm{dCIDR}+\mathrm{PGF}_{2 \alpha}$ treatment had a greater percentage of cows with PS = 0 and a lesser percentage of cows with PS $=5$ (Figure 2 ). Treatment did not affect the number of cows with a PS $=3$. We did observe an effect of PS after CIDR removal on conception rate for TAI. Cows with PS = 0 after CIDR removal had greater conception rate to the TAI than cows with PS $=3$ or 5 (Figure $3 ; P$ $<0.001)$. We also observed an effect of BCS on con- 


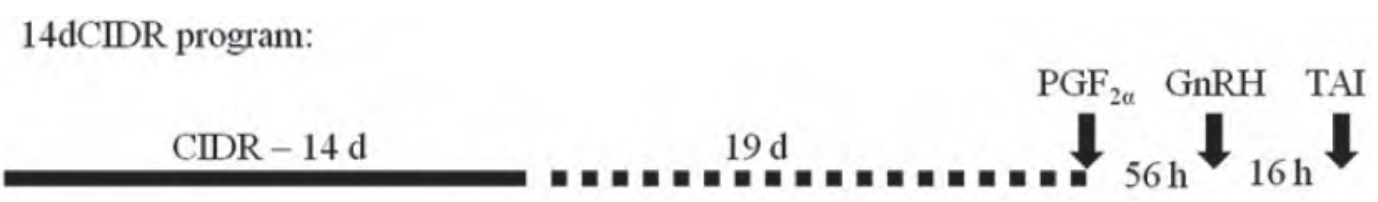

$14 \mathrm{dCIDR}+\mathrm{PGF}_{2 \alpha}$ program:

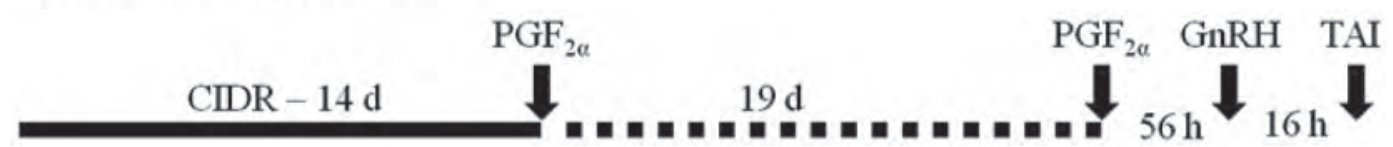

Figure 1. Timeline for treatment administration for cows assigned to $14 \mathrm{dCIDR}$ and $14 \mathrm{dCIDR}+\mathrm{PGF} \mathrm{p}_{2 \alpha}$ programs $(14 \mathrm{dCIDR}=\mathrm{CIDR}$ in, 14 $\mathrm{d}, \mathrm{CIDR}$ out; $14 \mathrm{dCIDR}+\mathrm{PGF}_{2 \alpha}=\mathrm{CIDR}$ in, $14 \mathrm{~d}, \mathrm{CIDR}$ out, and $\left.\mathrm{PGF}_{2 \alpha}\right)$. CIDR = intravaginal controlled internal drug release device (1.38 $\mathrm{g}$ of progesterone; Pfizer Animal Health, New York, NY); $\mathrm{PGF}_{2 \alpha}=5 \mathrm{~mL}$ of Lutalyse (i.m.; $25 \mathrm{mg}$ of dinoprost tromethamine; Pfizer Animal Health); GnRH $=2 \mathrm{~mL}$ of Factrel (Pfizer Animal Health); TAI = timed AI.

ception rate at the TAI $(P<0.05)$. Conception rate increased by approximately 10 percentage points for every half-score increase in BCS from 2.0 to 3.0 (Figure 4). Calving season had an effect on conception rate at the TAI $[P<0.001 ;$ carry-over, $148 / 296(50.0 \%)$ and spring calving, 153/491 (31\%); 234 cows were classified as unknown calving season]. We found no effect of PS, BCS, or calving season on second AI conception rate. For total number of pregnancies (first and second AI), we found an effect of PS [365/647 (56\%), 87/175 (50\%), and 80/199 (40\%) for PS $=0,3$, and 5, respectively; $P$ $<0.01]$, BCS [109/251 (43\%), 236/453 (52\%), 148/251 $(59 \%)$, and $39 / 66(59 \%)$ for $\mathrm{BCS}=2,2.5,3$, and 3.5 , respectively; $P<0.01]$, and calving season [170/296 $(57 \%)$ and $221 / 491(45 \%)$ for carry-over and spring, respectively; $P<0.01]$.
The average interval from first to second AI was 20.3 \pm 0.3 d. Paint score at CIDR removal had an effect on the overall frequency of cows returning to estrus on a given day after TAI $(P<0.05$; Figure 5$)$. A greater percentage of cows with PS $=0$ were in estrus 20 to $24 \mathrm{~d}$ after TAI compared with cows with PS 3 or 5 [129/261 (49\%) vs. $72 / 185(39 \%) ; P<0.05]$, and a greater percentage of PS $=3$ to 5 cows were in estrus 9 to $11 \mathrm{~d}$ after TAI compared with cows with PS $=0$ [27/185 (15\%) vs. $14 / 261(5 \%) ; P<0.01]$.

Although the injection of $\mathrm{PGF}_{2 \alpha}$ at CIDR removal did not increase conception rate to TAI (Table 1), it did decrease the percentage of cows with PS $=5$ after CIDR removal (Figure 2). Cows with a PS $=5$ may have had a luteal phase that eclipsed the duration of the CIDR treatment or may have been anovular (non-

Table 1. First AI and second AI conception rate and total pregnancies for cows treated with different reproductive programs (14dCIDR and $14 \mathrm{dCIDR}+\mathrm{PGF}_{2 \alpha}$ ) that used a controlled internal drug release (CIDR) device containing progesterone to presynchronize the estrous cycle before a timed AI (TAI)

\begin{tabular}{|c|c|c|c|}
\hline Item & \multicolumn{2}{|c|}{ Treatment $^{1}$} & Total \\
\hline Cows, no. & 523 & 498 & 1,021 \\
\hline Second AI conception rate, ${ }^{3}$ no./no (\%) & $58 / 194(29.9)$ & $42 / 175(24.0)$ & $100 / 369(27.1)$ \\
\hline Total pregnancies, ${ }^{4}$ no. $/$ no $(\%)$ & $273 / 523(52.2)$ & $259 / 498(52.0)$ & $532 / 1,021(52.1)$ \\
\hline
\end{tabular}

${ }_{1}^{1} 14 \mathrm{dCIDR}=\mathrm{CIDR}$ in, $14 \mathrm{~d}, \mathrm{CIDR}$ out; $14 \mathrm{dCIDR}+\mathrm{PGF}_{2 \alpha}=$ CIDR in, $14 \mathrm{~d}$, CIDR out, and PGF P $_{2 \alpha}$ Cows in both treatments were treated with $\mathrm{PGF}_{2 \alpha} 19 \mathrm{~d}$ after CIDR removal, GnRH $56 \mathrm{~h}$ after $\mathrm{PGF}_{2 \alpha}$, and TAI $16 \mathrm{~h}$ after GnRH (Figure 1).

${ }^{2}$ Numbers of pregnant cows after first AI/total number of cows with first AI.

${ }^{3}$ Numbers of pregnant cows after second AI/total number of cows with second AI. If a cow had not received a second insemination or was $<25$ $\mathrm{d}$ after second insemination when she was diagnosed as pregnant, then she was not included in the analyses of second AI conception rate.

${ }^{4}$ The total number of pregnancies after first and second AI was based on known pregnancies at the time of pregnancy diagnosis (the cow had to be at least $25 \mathrm{~d}$ pregnant). Seventy-six cows ( $3714 \mathrm{dCIDR}$ and $3914 \mathrm{dCIDR}+\mathrm{PGF}_{2 \alpha}$ ) received a second AI but were $<25 \mathrm{~d}$ since the second insemination. These cows, if pregnant, did not contribute to the total number of pregnancies in the analyses. 


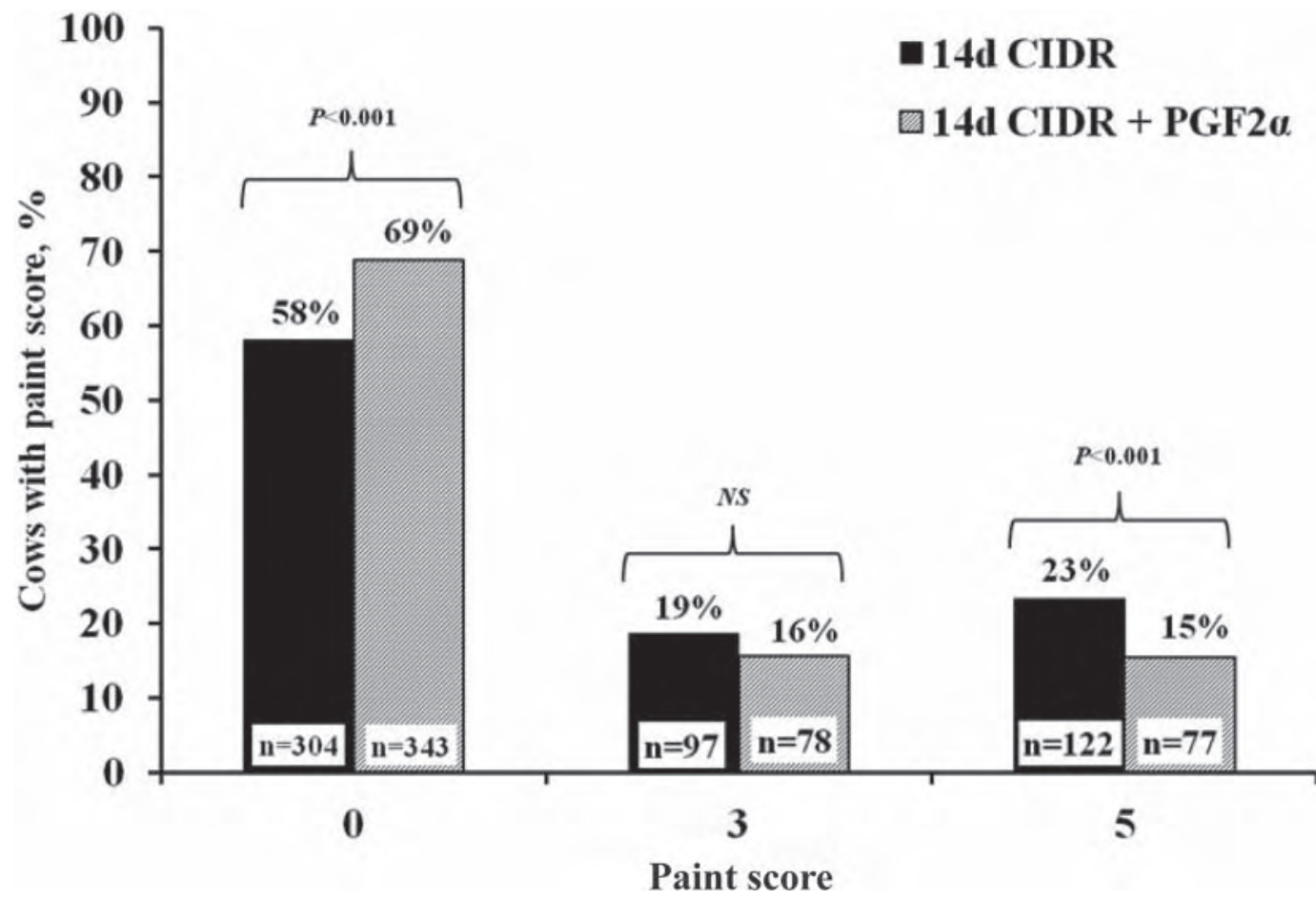

Figure 2. Percentage and number (n) of cows with a paint score (PS) of 0 (all paint removed, indicative of estrus), 3 (paint partially removed), or 5 (no paint removed; indicative of no estrus) for $14 \mathrm{dCIDR}$ (black bars; CIDR in, $14 \mathrm{~d}$, CIDR out) and $14 \mathrm{dCIDR}^{\mathrm{P}} \mathrm{PGF} \mathrm{F}_{2 \alpha}$ (hatched bars; CIDR in, $14 \mathrm{~d}$, CIDR out, and $\mathrm{PGF}_{2 \alpha}$ ). The PS was measured after the CIDR removal (approximately $22 \mathrm{~d}$ before the timed AI) to assess the response of cows to the presynchronization. The $P$-value above the bar represents the results of a chi-squared test for the comparison of treatment for cows with PS $=0,3$, or 5 .

cycling). A cow with a functional CL when treated with $\mathrm{PGF}_{2 \alpha}$ theoretically would regress the CL and move from a $\mathrm{PS}=5$ to a $\mathrm{PS}=0$ (indicative of estrus). This

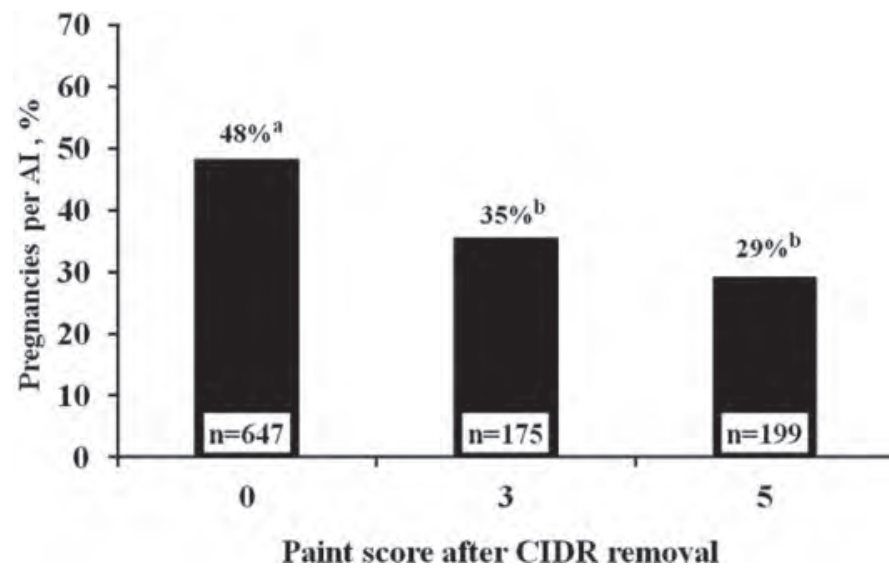

Figure 3. Conception rate (number of pregnant cows divided by the number of AI; pregnancies per AI) to the timed AI for cows with a paint score (PS) of 0 (all paint removed, indicative of estrus), 3 (paint partially removed), or 5 (no paint removed; indicative of no estrus) after the CIDR was removed. The PS was measured after the CIDR removal (approximately $22 \mathrm{~d}$ before the timed AI) to assess the response of cows to the presynchronization. ${ }^{\mathrm{a}, \mathrm{b}}$ Bars with different letters differ at $P<0.05$ (chi-squared test). would explain the shift among cows treated with $\mathrm{PGF}_{2 \alpha}$ out of PS $=5$ and into PS $=0$ (Figure 2 ).

We measured PS after the CIDR removal (approximately $22 \mathrm{~d}$ before the TAI) to assess the response of

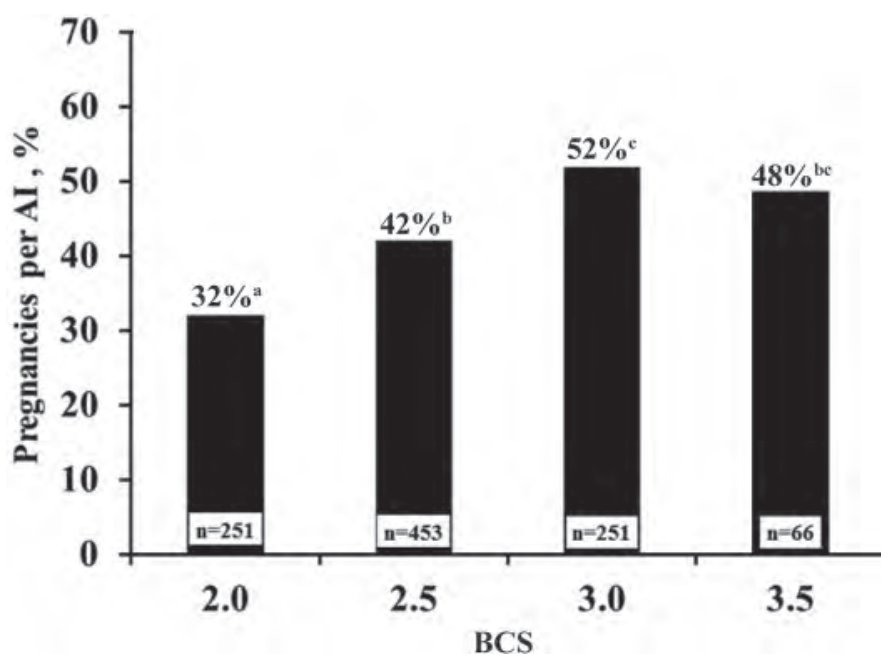

Figure 4. Conception rate (number of pregnant cows divided by the number of AI; pregnancies per AI) to the timed AI for cows with a BCS from 2.0 to 3.5. ${ }^{a-c}$ Bars with different letters differ at $P<0.05$ (chi-squared test). 


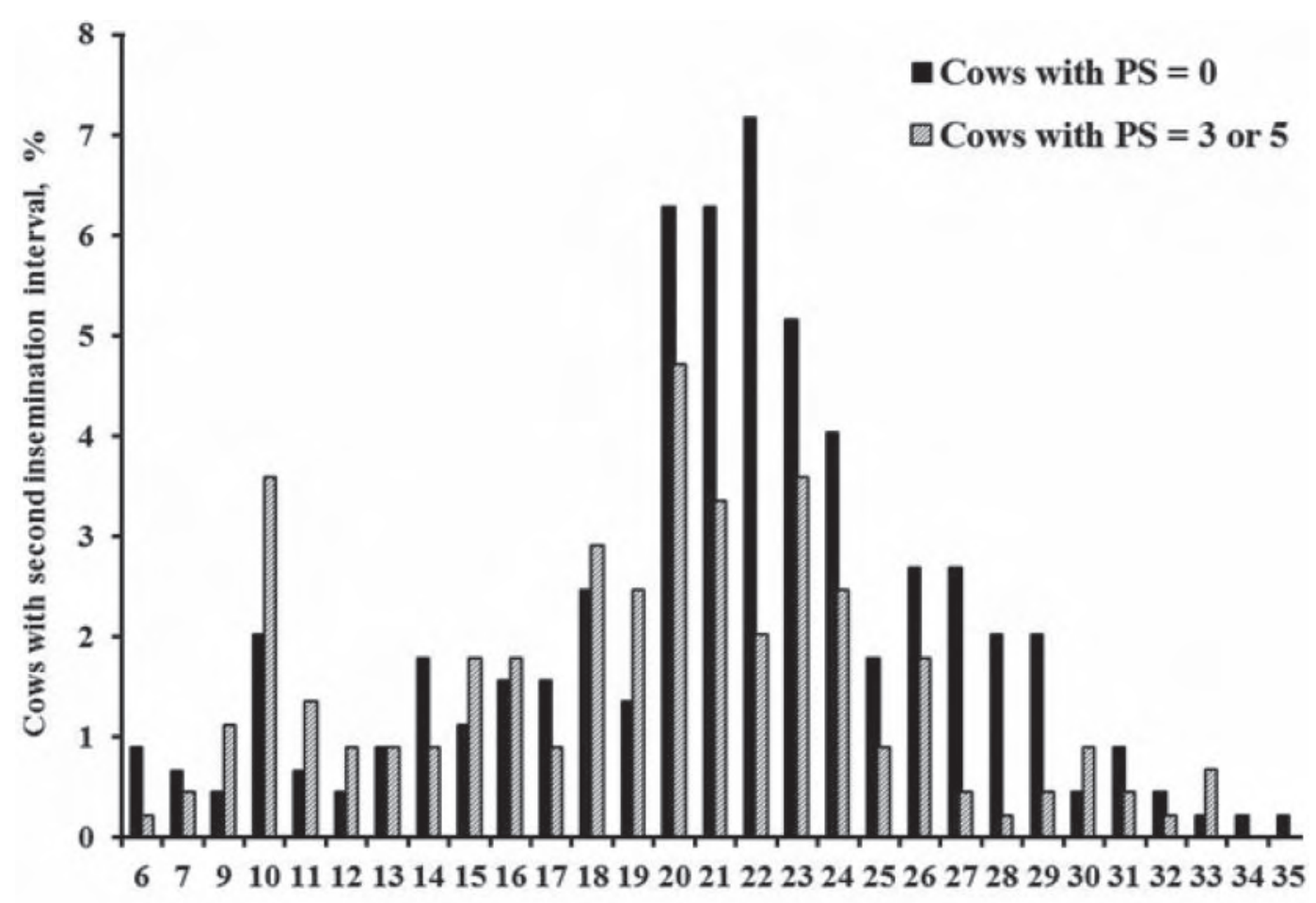

Days after first insemination

Figure 5. Percentage of cows with respective intervals from timed AI to second AI for cows with paint score (PS) $=0$ (black bars) or PS $=3$ or 5 (hatched bars). The PS was measured after the CIDR removal (approximately $22 \mathrm{~d}$ before the time AI) to assess the response of cows to the presynchronization.

cows to the presynchronization. Conception rate to TAI for cows with a PS $=0$ after presynchronization was greater than for cows with a PS $=3$ or 5 (Figure 3 ). The better fertility among cows with a PS $=0$ was perhaps because these cows came into estrus after the presynchronization. This population of cows had better synchrony for subsequent TAI compared with those cows that did not come into estrus (PS $=3$ or 5 ). For cows coming into estrus within $5 \mathrm{~d}$ after the CIDR removal (responded to presynchronization), the 19-d interval to $\mathrm{PGF}_{2 \alpha}$ should enable the complete maturation of the CL and the development a dominant follicle during the second half of the estrous cycle. The injection of $\mathrm{PGF}_{2 \alpha}$ on $\mathrm{d} 19$ is expected to regress the CL in these cows so that the dominant follicle can fully mature and ovulate in response to the injection of $\mathrm{GnRH}(56 \mathrm{~h}$ after $\left.\mathrm{PGF}_{2 \alpha}\right)$. Complete luteolysis and the ovulation of a mature dominant follicle should result in the greatest conception rate to TAI ( $16 \mathrm{~h}$ after $\mathrm{GnRH}$; Stevenson and Phatak, 2010). Cows that do not come into estrus after CIDR removal could be noncycling (Lucy et al., 1990) or could be cycling but poorly synchronized (i.e., may not be in the late luteal phase at the time of the $\mathrm{PGF}_{2 \alpha}, \mathrm{GnRH}$, and TAI).
We observed an 11-percentage-point increase in the percentage of cows with $\mathrm{PS}=0$ for the $14 \mathrm{dCIDR}+\mathrm{PGF}_{2 \alpha}$ treatment and a 19-percentage-point increase in conception rate for cows with $\mathrm{PS}=0$ compared with $\mathrm{PS}=5$. The combined effect of the 2 responses (11\% multiplied by $19 \%$ ) is approximately 2 percentage points. This combined effect approximates the overall advantage that we observed for conception rate in the $14 \mathrm{dCIDR}+\mathrm{PGF}_{2 \alpha}$ cows. To be a more effective treatment, the addition of the $\mathrm{PGF}_{2 \alpha}$ to the 14dCIDR program would need to cause a greater increase in the percentage of cows with PS $=0$ after CIDR removal. The overall response to the $\mathrm{PGF}_{2 \alpha}$ treatment most likely depends on the percentage of cycling cows in the herd. Herds with a greater number of cycling cows would theoretically have more cows with a CL and a better overall response to the $\mathrm{PGF}_{2 \alpha}$ treatment at CIDR removal. An alternative possibility is that the percentage of cows with a CL at the end of a 14-d CIDR treatment may be too low and inconsequential to detect a beneficial response to the addition of $\mathrm{PGF}_{2 \alpha}$ to the program. If this is the case, then treating with $\mathrm{PGF}_{2 \alpha}$ at CIDR withdrawal will not increase conception rate to the TAI. Regardless of the underlying factors, the gains achieved by increasing the 
percentage of cows in estrus after CIDR treatment are tempered by the modest improvement in pregnancies per AI for cows with PS $=0$ versus $\mathrm{PS}=5$ (Figure 3 ).

Cows with a BCS $\geq 3.0$ (approximately one-third of the study cows) had a conception rate of $>50 \%$ to the TAI, nearly 20 percentage points greater than cows with $\mathrm{BCS}=2$ (Figure 4 ). The TAI programs that we tested, therefore, were similar to other TAI programs in that cows with greater BCS had a greater conception rate to TAI compared with cows in lower BCS (Souza et al., 2007 ). We found that $30 \%$ of cows with $\mathrm{BCS}=2$ had a $\mathrm{PS}=5$ after CIDR removal. The comparable number for cows with greater BCS was lower (approximately $15 \%$ ). The greater percentage of PS $=5$ cows within the $\mathrm{BCS}=2$ group indicates an association between BCS and cyclicity within the population of cows that we used (many of the PS $=5$ were presumably not cycling). Cows that are not cycling when entering reproductive programs generally do not perform well because they do not have a CL at the time of $\mathrm{PGF}_{2 \alpha}$ before TAI. They may ovulate in response to $\mathrm{GnRH}$ but are predisposed to a short estrous cycle that precludes conception to the TAI. We did observe a greater percentage of PS $=3$ or 5 than PS $=0$ cows returning to estrus on $\mathrm{d} 9$ to 11 after the TAI (Figure 5). This population of PS $=3$ or 5 cows may represent the cows that were not cycling, had ovulated in response to $\mathrm{GnRH}$, and had a short estrous cycle (Short et al., 1990; Gümen et al., 2003).

An interesting aspect of this trial was the unexpected effect that the presynchronization response had on the interval to second $\mathrm{AI}$ in cows that failed to get pregnant to TAI. We found that cows with a PS = 0 after CIDR removal had a more typical 20- to 24-d second AI return interval (Figure 5). The cows that had PS $=3$ or 5 had a less distinct pattern within the 20- to 24-d window and also had a large percentage of cows returning to estrus from d 9 to 11 (possible short cycle). Cows that had a PS $=0$ after CIDR removal responded to the presynchronization and were theoretically cycling. Based on their return interval, these cows evidently responded appropriately to the TAI as well (regressed their CL and ovulated) but did not become pregnant. The TAI program conferred an advantage at second AI in cycling cows because the return to estrus depends in part on the time of ovulation (and the ensuing estrous cycle) after the TAI. A potential advantage was conferred to the PS $=3$ or 5 cows because the cows returning to estrus from d 9 to 11 were inseminated within 2 wk after the unsuccessful TAI.

In conclusion, adding a luteolytic $\mathrm{PGF}_{2 \alpha}$ injection at CIDR removal of a 14-d CIDR presynchronization program increased the percentage of cows that came into estrus after CIDR withdrawal. The treatment did not, however, cause a significant increase in conception rate to the subsequent TAI, perhaps because the improvement in presynchronization estrus response was relatively small. Cows coming into estrus after the CIDR treatment $(\mathrm{PS}=0)$ had a greater conception rate to the TAI compared with cows that did not come into estrus (PS $=5$ ). These same cows (in estrus after CIDR removal) had a more typical second AI return interval compared with cows that did not come into estrus. Body condition score was an additional overriding factor in the conception rate response (better-conditioned cows were more likely to be pregnant to TAI). A 14-d CIDR program can be used in postpartum dairy cows for TAI but it is not necessary to treat cows with $\mathrm{PGF}_{2 \alpha}$ at CIDR removal. Monitoring the estrous response to the CIDR treatment may give a preliminary indication of subsequent TAI success.

\section{REFERENCES}

Ahmad, N., F. N. Schrick, R. L. Butcher, and E. K. Inskeep. 1995. Effect of persistent follicles on early embryonic losses in beef cattle. Biol. Reprod. 52:1129-1135.

Anderson, L. H., C. M. McDowell, and M. L. Day. 1996. Progestininduced puberty and secretion of luteinizing hormone in heifers. Biol. Reprod. 54:1025-1031.

Christian, R. E., and L. E. Casida. 1948. The effects of progesterone in altering the estrous cycle of the cow. J. Anim. Sci. 7:540. (Abstr.)

Garrett, J. E., R. D. Geisert, M. T. Zavy, L. K. Gries, R. P. Wettemann, and D. S. Buchanan. 1988. Effect of exogenous progesterone on prostaglandin $\mathrm{F} 2$ alpha release and the interestrous interval in the bovine. Prostaglandins 36:85-96.

Gümen, A., J. N. Guenther, and M. C. Wiltbank. 2003. Follicular size and response to Ovsynch versus detection of estrus in anovular and ovular lactating dairy cows. J. Dairy Sci. 86:3184-3194.

Kinder, J. E., F. N. Kojima, E. G. Bergfeld, M. E. Wehrman, and K. E. Fike. 1996. Progestin and estrogen regulation of pulsatile LH release and development of persistent ovarian follicles in cattle. J. Anim. Sci. 74:1424-1440.

Lauderdale, J. W. 2009. ASAS Centennial Paper: Contributions in the Journal of Animal Science to the development of protocols for breeding management of cattle through synchronization of estrus and ovulation. J. Anim. Sci. 87:801-812.

Leitman, N. R., D. C. Busch, D. A. Mallory, D. J. Wilson, M. R. Ellerseick, M. F. Smith, and D. J. Patterson. 2009. Comparison of long-term CIDR-based protocols to synchronize estrus in beef heifers. Anim. Reprod. Sci. 114:345-355.

Lucy, M. C., H. J. Billings, W. R. Butler, L. R. Ehnis, M. J. Fields, D. J. Kesler, J. E. Kinder, R. C. Mattos, R. E. Short, W. W. Thatcher, R. P. Wettemann, J. V. Yelich, and H. D. Hafs. 2001. Efficacy of an intravaginal progesterone insert and an injection of $\mathrm{PGF}_{2 \alpha}$ for synchronizing estrus and shortening the interval to pregnancy in postpartum beef cows, peripubertal beef heifers, and dairy heifers. J. Anim. Sci. 79:982-995.

Lucy, M. C., W. W. Thatcher, and K. L. MacMillan. 1990. Ultrasonic identification of follicular populations and return to estrus in early postpartum dairy cows given intravaginal progesterone for 15 days. Theriogenology 34:325-340.

Lynch, P. R., K. L. Macmillan, and V. K. Taufa. 1999. Treating cattle with progesterone as well as a GnRH analogue affects oestrous cycle length and fertility. Anim. Reprod. Sci. 56:189-200.

Macmillan, K. L., V. K. Taufa, D. R. Barnes, A. M. Day, and R. Henry. 1988. Detecting estrus in synchronized heifers-using tailpaint and an aerosol raddle. Theriogenology 30:1099-1114.

Odde, K. G. 1990. A review of synchronization of estrus in postpartum cattle. J. Anim. Sci. 68:817-830. 
Patterson, D. J., G. H. Kiracofe, J. S. Stevenson, and L. R. Corah. 1989. Control of the bovine estrous cycle with melengestrol acetate (MGA): A review. J. Anim. Sci. 67:1895-1906.

Revah, I., and W. R. Butler. 1996. Prolonged dominance of follicles and reduced viability of bovine oocytes. J. Reprod. Fertil. 106:39-47.

Roche, J. F., E. J. Austin, M. Ryan, M. O'Rourke, M. Mihm, and M G. Diskin. 1999. Regulation of follicle waves to maximize fertility in cattle. J. Reprod. Fertil. Suppl. 54:61-71.

Schafer, D. J., J. F. Bader, J. P. Meyer, J. K. Haden, M. R. Ellersieck, M. C. Lucy, M. F. Smith, and D. J. Patterson. 2007. Comparison of progestin-based protocols to synchronize estrus and ovulation before fixed-timed artificial insemination in postpartum beef cows. J. Anim. Sci. 85:1940-1945

Short, R. E., R. A. Bellows, R. B. Staigmiller, J. G. Berardinelli, and E. E. Custer. 1990. Physiological mechanisms controlling an- estrus and infertility in postpartum beef cattle. J. Anim. Sci. 68:799-816.

Sirois, J., and J. E. Fortune. 1990. Lengthening the bovine estrous cycle with low levels of exogenous progesterone: A model for studying ovarian follicular dominance. Endocrinology 127:916-925.

Souza, A. H., A. Gümen, E. P. Silva, A. P. Cunha, J. N. Guenther, C. M. Peto, D. Z. Caraviello, and M. C. Wiltbank. 2007. Supplementation with estradiol-17beta before the last gonadotropin-releasing hormone injection of the Ovsynch protocol in lactating dairy cows. J. Dairy Sci. 90:4623-4634.

Stevenson, J. S., and A. P. Phatak. 2010. Rates of luteolysis and pregnancy in dairy cows after treatment with cloprostenol or dinoprost. Theriogenology 73:1127-1138. 